\title{
The impact of heat treatment on the microstructure of a clay ceramic and its thermal and mechanical properties
}

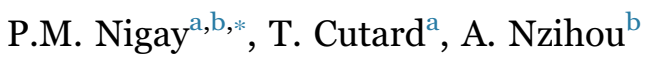

a Université de Toulouse, Mines Albi, CNRS, Institut Clément Ader, Campus Jarlard, Route de Teillet, F-81013 Albi Cedex 09, France
b Université de Toulouse, Mines Albi, CNRS, Centre RAPSODEE, Campus Jarlard, Route de Teillet, F-81013 Albi Cedex 09, France

Keywords:

Clay

Ceramic

Porosity

Young's modulus

Thermal conductivity

\begin{abstract}
A B S T R A C T
This paper presents the results of an experimental study on the microstructure, the thermal and the mechanical properties of a clay-based ceramic used in building applications. The X-ray tomography analysis showed a layered microstructure of clay with $200 \mu \mathrm{m}$ sheets of porosity after the extrusion process. The gas release from the dehydration, dehydroxylation and decarbonation induced a 7 vol\% formation of porosity during the heat treatment of the clay-based ceramic up to $850^{\circ} \mathrm{C}$. The porosity increase and the development of metakaolin led to a $38 \%$ decrease in the thermal conductivity. On the other hand, the Young's modulus of the clay-based ceramic was conserved due to the formation of smaller pores than the $200 \mu \mathrm{m}$ sheets of porosity. The densification and the crystallization of amorphous phases also led to a $110 \%$ increase of the Young's modulus from $850{ }^{\circ} \mathrm{C}$ to $1050^{\circ} \mathrm{C}$. The Young's modulus of the clay-based ceramic was only decreased by the $\beta \rightarrow \alpha$ quartz inversion of the cooling due to sand addition. Hence, this study provided a useful insight into how the microstructure of fired clay bricks can be specifically transformed by the porosity during the heat treatment to control the thermal and mechanical properties.
\end{abstract}

\section{Introduction}

Terracotta is a noble material used in the fields of sculpture, earthenware and construction since millennia [1]. The expression changed over the years to describe the building materials such as fired clay bricks. Fired clay bricks are valuable materials due to their resistance and insulation performances. However, the combination of thermal and mechanical properties is the result of a long process.

The raw clay extracted from sedimentation pools is mixed with sand and water. The plastic mixture is shaped in the form of bricks using an extrusion process [2]. The water is also removed by a drying process at temperatures up to $100^{\circ} \mathrm{C}$. The drying is promoted by the large particle size of the sand. The clay bricks experience afterwards a heat treatment at temperatures of $800^{\circ} \mathrm{C}$ up to $1200{ }^{\circ} \mathrm{C}$. In fact, the heat treatment temperatures are adapted to the purpose of the application [3]. The clay bricks are heat treated at temperatures around $800{ }^{\circ} \mathrm{C}$ to obtain high thermal properties. On the other hand, the fired clay bricks with high mechanical properties are obtained by heat treatment at temperatures around $1200{ }^{\circ} \mathrm{C}$. This means that the fired clay-bricks present a trade-off between their thermal and mechanical properties. The trade-off comes to an issue since the fired clay bricks are used in building applications for resistance and insulation purposes at the same time [4].

In recent years, many studies have shown the impact of the heat treatment temperature on the properties of fired clay bricks $[5,6]$. The apparent trade-off between their thermal and mechanical properties was related to the microstructure. The clay bricks heat treated at around $800{ }^{\circ} \mathrm{C}$ presented a high percentage of porosity. The low thermal conductivity of air in these pores $(0.026 \mathrm{~W} / \mathrm{m} / \mathrm{K})$ leads to the acquisition of high thermal properties [7]. A recent study demonstrated that thermal properties are also enhanced by the anisotropy of the fired clay bricks [8]. In fact, the heat conduction is highly limited through the plane of extrusion. The fired clay bricks present higher thermal properties in the direction of the thermal gradient of a wall. However, the literature indicates that the mechanical properties of the clay bricks are limited in the case of a heat treatment at around $800{ }^{\circ} \mathrm{C}$. The low temperatures prevent from the transformation of clay minerals in thermally stable phases [9]. Moreover, the mechanical properties are restrained by the presence of pores acting as defects in the microstructure [10].

According to the literature, the heat treatment of clay bricks at around $1200{ }^{\circ} \mathrm{C}$ leads to the acquisition of high mechanical properties. The sintering induces a consolidation of the clay bricks by a formation of necks between the particles [11]. The mechanical properties are also

\footnotetext{
* Corresponding author at: Université de Toulouse, Mines Albi, CNRS, Centre RAPSODEE, Campus Jarlard, Route de Teillet, F-81013 Albi Cedex 09, France.

E-mail address: pmnigay@mines-albi.fr (P.M. Nigay).
} 
enhanced by the densification of the fired clay bricks. In fact, the densification leads to an elimination of pores acting as defects in the microstructure [12]. Some other studies attributed the acquisition of high mechanical properties to the transformation of the clay minerals into stable minerals such as mullite [13]. However, the literature has shown that the thermal properties of the fired clay bricks are limited in the case of a heat treatment at temperatures around $1200{ }^{\circ} \mathrm{C}$. The elimination of pores reduces the proportion of air in the fired clay bricks, moreover, the thermal properties are limited by the progressive reduction of the anisotropy with the heat treatment [14].

The literature on the microstructure and the properties of the fired clay bricks with the heat treatment temperature is consistent. However, the research focuses on the characterization of the thermal and mechanical properties after heat treatment. The objective of this study is to investigate how the microstructure of fired clay bricks can be transformed during the heat treatment to control the thermal and mechanical properties. Hence, the study starts from the microstructure of a clay-based ceramic after the extrusion process. The experiments show the impact of the dehydration, dehydroxylation and decarbonation on the porosity of the clay-based ceramic during the heat treatment. The evolution of the porosity is also related to the evolution of the thermal and mechanical properties of the clay-based ceramic with the heat treatment temperature. The impact of the percentage of porosity on the thermal properties is separated from the effect of the solid skeleton using the Landauer's model. The impact of the solid skeleton is further confirmed by the quantities of mineral phases in relation with their properties obtained from the literature. Hence, this study shows how the microstructure of fired clay bricks can be specifically transformed by the porosity during the heat treatment to control the thermal and mechanical properties.

\section{Materials and methods}

\subsection{Production of the clay-based ceramic}

The clay-based ceramic investigated in this research was made of clay, sand and water. The clay was extracted as one batch in a clay quarry to ensure homogeneity. The clay was also ground at the laboratory with a $1 \mathrm{~mm}$ rolling. The clay-based ceramic mixture was prepared in a $70 / 30 \mathrm{wt} \%$ proportion introducing $8.4 \mathrm{~kg}$ of clay and $3.6 \mathrm{~kg}$ of sand in a kneading bowl. The $12 \mathrm{~kg}$ batch had a kneading for 10 min with an addition of water up to $17 \mathrm{wt} \%$. The mixture was after extruded with an 8bars pressure to form a clay-based ceramic of $180 \times 80 \times 18 \mathrm{~mm}^{3}$. The clay-based ceramic experienced a drying at $25^{\circ} \mathrm{C}, 65^{\circ} \mathrm{C}$ and $105^{\circ} \mathrm{C}$ for $24 \mathrm{~h}$ at each temperature in an electrical oven. The samples used for the experiments of this study were cut in the dried ceramic and rectified by polishing. The samples analyzed after heat treatment were heated in an electrical furnace (Nabertherm Controller C320) at different temperatures.

\subsection{Determination of the composition}

The inorganic elements of the clay, of the sand and of the clay-based ceramic mixture were measured with an ICP-AES instrument (Jobin Yvon Ultima 2). The materials were dissolved in a mixture of perchloric and hydrofluoric acid heated at $80{ }^{\circ} \mathrm{C}$ for $30 \mathrm{~min}$. The solutions were diluted 10 times in purified water before the analyses. The concentrations of the inorganic elements obtained are reported in Table 1 as equivalent oxides. The aluminum and silicon oxides which are the main oxides of the clay minerals are presented separately. The other oxides include the calcium, magnesium and iron oxides. The distribution of oxides was placed on a ternary diagram of composition with common minerals of the terracotta. The position of the oxide equilibrium provided a prediction of the mineralogical transformations.

The mineralogical study was completed by X-ray diffraction (XRD) analyses using a Phillips Panalytical X'pert Pro MPD diffractometer.
Table 1

Oxide distribution of the main inorganic elements of the clay, of the sand and of the claybased ceramic mixture.

\begin{tabular}{cccc}
\hline Sample & \multicolumn{3}{c}{ Distribution of oxides (wt\%) } \\
\cline { 2 - 4 } & $\mathrm{Al}_{2} \mathrm{O}_{3}$ & $\mathrm{SiO}_{2}$ & Others \\
\hline Clay & 16.8 & 44.8 & 38.4 \\
Sand & 16.8 & 62.4 & 20.8 \\
Mixture & 16.8 & 50.1 & 33.1 \\
\hline
\end{tabular}

The samples were analyzed as powders after heat treatment at $30^{\circ} \mathrm{C}$, $600{ }^{\circ} \mathrm{C}, 800{ }^{\circ} \mathrm{C}, 900{ }^{\circ} \mathrm{C}$ and $1000{ }^{\circ} \mathrm{C}$ with a $5^{\circ} \mathrm{C} / \mathrm{min}$ heating rate. Data were collected on a range of $2 \theta$ from $5^{\circ}$ to $65^{\circ}$ for each $0.017^{\circ}$ with a CuKa radiation source $(\lambda=1.5405 \AA)$. The same automatic treatment of the background was applied to the scan of the different samples in the $X^{\prime}$ Pert HighScore Plus software. The identification of the minerals was carried out matching the ICDD database lines to the diffraction peaks. The content of minerals was measured by the RIR technique using the intensity of the diffraction peaks. A calibration was first performed using a 50/50 wt\% mixture of the samples with an alumina reference. The quartz content was estimated comparing the intensity of its highest peak to the intensity of the highest peak of the reference. The intensity of the highest peak of the quartz phase was after compared to the intensity of the highest peak of other minerals in the samples.

\subsection{Characterization of the microstructure}

The heat flow and weight loss of the clay-based ceramic were measured as a function of the temperature using differential thermal analysis (DTA). The unfired samples were analyzed as $200 \mathrm{mg}$ cylinders with a $5 \mathrm{~mm}$ diameter with a Setaram 92 instrument. Data were collected under air from $30^{\circ} \mathrm{C}$ to $1100{ }^{\circ} \mathrm{C}$ at a heating rate of $5{ }^{\circ} \mathrm{C} / \mathrm{min}$. The deformation of the clay-based ceramic was also measured as a function of the temperature using thermo-mechanical analyses (TMA). The unfired samples were analyzed in the form of $200 \mathrm{mg}$ cylinders with a $5 \mathrm{~mm}$ diameter with a Setsys $16 / 18$ apparatus. Data were collected under air from $30^{\circ} \mathrm{C}$ to $1100{ }^{\circ} \mathrm{C}$ at a heating rate of $5{ }^{\circ} \mathrm{C} / \mathrm{min}$. The same conditions were used for TMA and DTA to provide a consistent estimate of the bulk density [15]. In fact, the bulk density of the clay-based ceramic $\left(\rho_{(\mathrm{T})}\right)$ was calculated as a function of the temperature from Eq. (1) using the weight loss, the shrinkage, the initial weight $\left(\mathrm{m}_{0}\right)$, the initial length $\left(\mathrm{l}_{0}\right)$ and the initial radius $\left(\mathrm{r}_{0}\right)$ of the samples.

$\rho_{(\mathrm{T})}=\frac{\mathrm{m}_{0}\left(1-\text { Weight }_{\text {Loss }}(\mathrm{T})\right.}{\pi \mathrm{r}_{0}{ }^{2} 1_{0}\left(1-\text { Shrinkage }_{(\mathrm{T})}\right)^{3}}$

The transposition of the uniaxial deformation in a volume deformation supposes an isotropic behavior of the clay-based ceramic. The claybased ceramic that was investigated in this study presented an anisotropic behavior. However, the evolution of the bulk density was controlled by the evolution of the weight loss due to an insignificant evolution of the deformation. The evolution of the weight loss is independent of the direction and disposes of this isotropic condition.

The porosity of the clay-based ceramic $\left(\varepsilon_{(\mathrm{T})}\right)$ was calculated as a function of the temperature from Eq. (2). The calculations were carried out using the bulk density of the clay-based ceramic $\left(\rho_{(\mathrm{T})}\right)$ and the true density of the particles $\left(\rho_{\text {True }}\right)$. The effect of the modifications in the mineral phases of the clay-based ceramic was included in the evolution of the bulk density with the temperature. The true density of the particles was then not depending on the heat treatment temperature. In fact, the true density was only measured by Helium pycnometer analyses after a heat treatment of the clay-based ceramic at the maximum temperature of $1100^{\circ} \mathrm{C}$ and a fine grinding to eliminate the porosity. The true density of the particles was equal to $2.72 \mathrm{~g} / \mathrm{cm}^{3}$. 
In this way, the percentage of porosity was determined in a continuous way at temperatures between $30{ }^{\circ} \mathrm{C}$ and $1100{ }^{\circ} \mathrm{C}$.

$\varepsilon_{(\mathrm{T})}=1-\frac{\rho_{(\mathrm{T})}}{\rho_{\text {True }}}$

The microstructure of the clay-based ceramic was observed by Xray tomography using the Synchroton facility at ESFR Grenoble. The samples were analyzed as $200 \mathrm{mg}$ cylinders after heat treatment at $950{ }^{\circ} \mathrm{C}$. The micrograph of the cross-section shows the solid skeleton in light grey colours and the porosity in a black colour. The cross-section scans were also used to build a 3D representation of the porosity using imaging software. The 3D representation of the porosity shows the porosity of the clay-based ceramic in a light grey colour.

\subsection{Determination of the thermal properties}

The thermal properties of the clay-based ceramic were measured by a transitory plane source method (Hot Disk AB TPS 2500). Samples were analyzed as twins of $30 \times 30 \times 5 \mathrm{~mm}^{3}$ using a nickel probe ( $3.189 \mathrm{~mm}$ radius). The thermal conductivity was calculated from the thermal response of the samples with the dimension and the power of the probe. The analyses were performed at room temperature after heat treatment at $30^{\circ} \mathrm{C}, 200{ }^{\circ} \mathrm{C}, 400{ }^{\circ} \mathrm{C}, 600{ }^{\circ}, 700^{\circ} \mathrm{C}, 800^{\circ} \mathrm{C}, 900^{\circ} \mathrm{C}$, $1000{ }^{\circ} \mathrm{C}$ and $1100{ }^{\circ} \mathrm{C}$ using a $5{ }^{\circ} \mathrm{C} / \mathrm{min}$ heating rate. The values of the thermal conductivity after heat treatment at $250^{\circ} \mathrm{C}, 450{ }^{\circ} \mathrm{C}, 650^{\circ} \mathrm{C}$ and $850{ }^{\circ} \mathrm{C}$ were also calculated by linear regression analyses. In this way, the thermal conductivity could be compared to the percentage of porosity on the exact ranges of evolution with the temperature. The ranges were determined from the measurements of the weight loss, of the deformation, of the heat flow and of the percentage of porosity which are continuous with the temperature.

\subsection{Determination of the mechanical properties}

The mechanical properties of the clay-based ceramic were measured by a resonant frequency analyzer (IMCE HT650). The samples of $60 \times 30 \times 5 \mathrm{~mm}^{3}$ were tested in a flexural mode. The Young's modulus was calculated from the fundamental resonance frequency and the samples dimensions. The analyses were performed with the temperature by introduction of the testing facility in an electrical furnace. The Young's modulus of the clay-based ceramic was then measured in a continuous way from $30^{\circ} \mathrm{C}$ to $1050{ }^{\circ} \mathrm{C}$.

\section{Results and discussion}

\subsection{Mineralogical transformations}

The oxide distributions of the clay, of the sand and of the clay-based ceramic mixture are displayed on the ternary diagram of composition in Fig. 1. The diagram also shows the minerals which are likely to form during the heat treatment. According to the literature, the clay minerals are transformed into an $\mathrm{Al} / \mathrm{Si}$ spinel phase $\left(\mathrm{Si}_{3} \mathrm{Al}_{4} \mathrm{O}_{12}\right)$. The phase is expected to transform at high temperatures into a more stable phase of mullite $\left(\mathrm{Si}_{2} \mathrm{Al}_{6} \mathrm{O}_{13}\right)$. However, the presence of minerals such as calcium carbonates increases the concentration of other oxides than the aluminum and silicon oxides. The calcium carbonates induce a shift in the oxide equilibrium of the clay on the ternary diagram of composition. Hence, the clay minerals are more likely to transform at high temperatures into calcium-rich crystallites such as gehlenite $\left(\mathrm{Ca}_{2} \mathrm{Al}_{2} \mathrm{SiO}_{7}\right)$. The recombination with the calcium oxides would start at the interface of the clay minerals and calcium carbonates. However, the clay minerals could also transform into wollastonite $\left(\mathrm{CaSiO}_{3}\right)$ in order to reach the oxide equilibrium.

The sand added to the clay-based ceramic for its thermal stability show an oxide distribution close to the silica pit $\left(\mathrm{SiO}_{2}\right)$. However, a combination with the oxides from the clay would modify the oxide

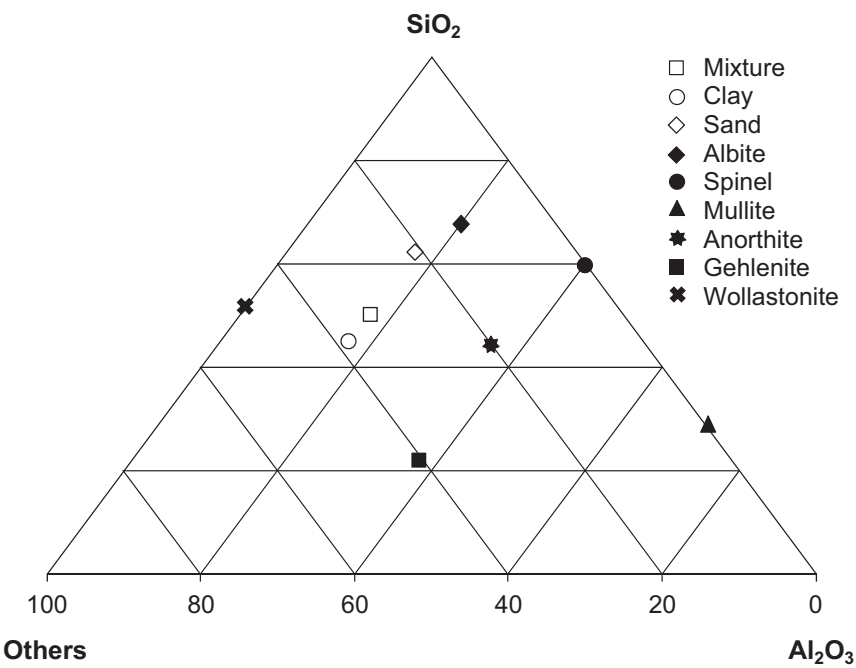

Fig. 1. Ternary diagram of composition with the clay, the sand and the clay-based ceramic mixture.

equilibrium of the sand. The minerals from the sand could transform into albite $\left(\mathrm{NaAlSi}_{3} \mathrm{O}_{8}\right)$, which is the sodium pole of plagioclase. Anorthite $\left(\mathrm{CaAl}_{2} \mathrm{Si}_{2} \mathrm{O}_{8}\right)$ which is the calcium pole of plagioclase could form at higher temperatures with a greater amount of energy. In fact, the oxide distribution of the clay-based ceramic mixture corresponds to the $70 \mathrm{wt} \%$ oxides of the clay and the $30 \mathrm{wt} \%$ oxides of the sand. The transformations of the clay-based ceramic are then unlikely to be the common transformations of the clay minerals. The energy supplied by the temperature should activate the transformations leading the clay and other minerals towards the global oxide equilibrium of the claybased ceramic mixture.

The X-ray diffraction (XRD) patterns of the clay-based ceramic are displayed after heat treatment at different temperatures in Fig. 2. The diffraction peaks show a presence of clay minerals after heat treatment at $30{ }^{\circ} \mathrm{C}$. The clay-based ceramic is composed for $26 \mathrm{wt} \%$ of halloysite $\left(\mathrm{Al}_{2} \mathrm{Si}_{2} \mathrm{O}_{5}(\mathrm{OH})_{4}\right)$ from the kaolinite-group. The illite-group minerals are present at $18 \mathrm{wt} \%$ with a regular illite $\left(\mathrm{KAl}_{3} \mathrm{Si}_{3} \mathrm{O}_{10}(\mathrm{OH})_{2}\right)$ and an illite stratified by montmorillonite layers. Furthermore, the XRD pattern of the clay-based ceramic shows a $12 \mathrm{wt} \%$ content of calcium carbonates in the form of calcite $\left(\mathrm{CaCO}_{3}\right)$. The minerals from the sand are also present with $26 \mathrm{wt} \%$ of quartz $\left(\mathrm{SiO}_{2}\right)$ and $13 \mathrm{wt} \%$ of alkali feldspar $\left(\mathrm{KAlSi}_{3} \mathrm{O}_{8}\right)$.

The XRD pattern after heat treatment at $600^{\circ} \mathrm{C}$ explains the transformations of the clay minerals during the heat treatment. The temperature increase leads to an elimination of the diffraction peak associated with halloysite (e.g., at $12^{\circ}$ ). In fact, the heat treatment induces a dehydroxylation of the kaolinite-group minerals from around $450{ }^{\circ} \mathrm{C}$. The split of the hydroxyl groups that assured a cohesion between the tetrahedral and the octahedral sheets induces a collapse of the clay layers [16]. Therefore, the dehydroxylation leads to an amorphization of halloysite into metakaolin $\left(\mathrm{Al}_{2} \mathrm{Si}_{2} \mathrm{O}_{7}\right)$ along with a water release as shown in Eq. (3).

$\mathrm{Al}_{2} \mathrm{Si}_{2} \mathrm{O}_{5}(\mathrm{OH})_{4}(s) \rightarrow \mathrm{Al}_{2} \mathrm{Si}_{2} \mathrm{O}_{7}(s)+2 \mathrm{H}_{2} \mathrm{O}(g)$

On the other hand, the clay minerals of the illite-group experience a dehydroxylation from $500{ }^{\circ} \mathrm{C}$ to $600{ }^{\circ} \mathrm{C}$. The diffraction peaks associated with the illite minerals remain on the XRD patterns up to $800^{\circ} \mathrm{C}$. In fact, the dehydroxylation of illite starts by a condensation of hydroxyl groups into water molecules [17]. The condensation of hydroxyl groups leaves an atom of oxygen between the tetrahedral and the octahedral sheets of the clay layers. This relocation avoids a collapse of the structure in contrast with kaolinite-group minerals. The dehydroxylation process only leads to a transformation of illite-group minerals in anhydrous illites $\left(\mathrm{KAl}_{3} \mathrm{Si}_{3} \mathrm{O}_{11}\right)$ along with a water release as 


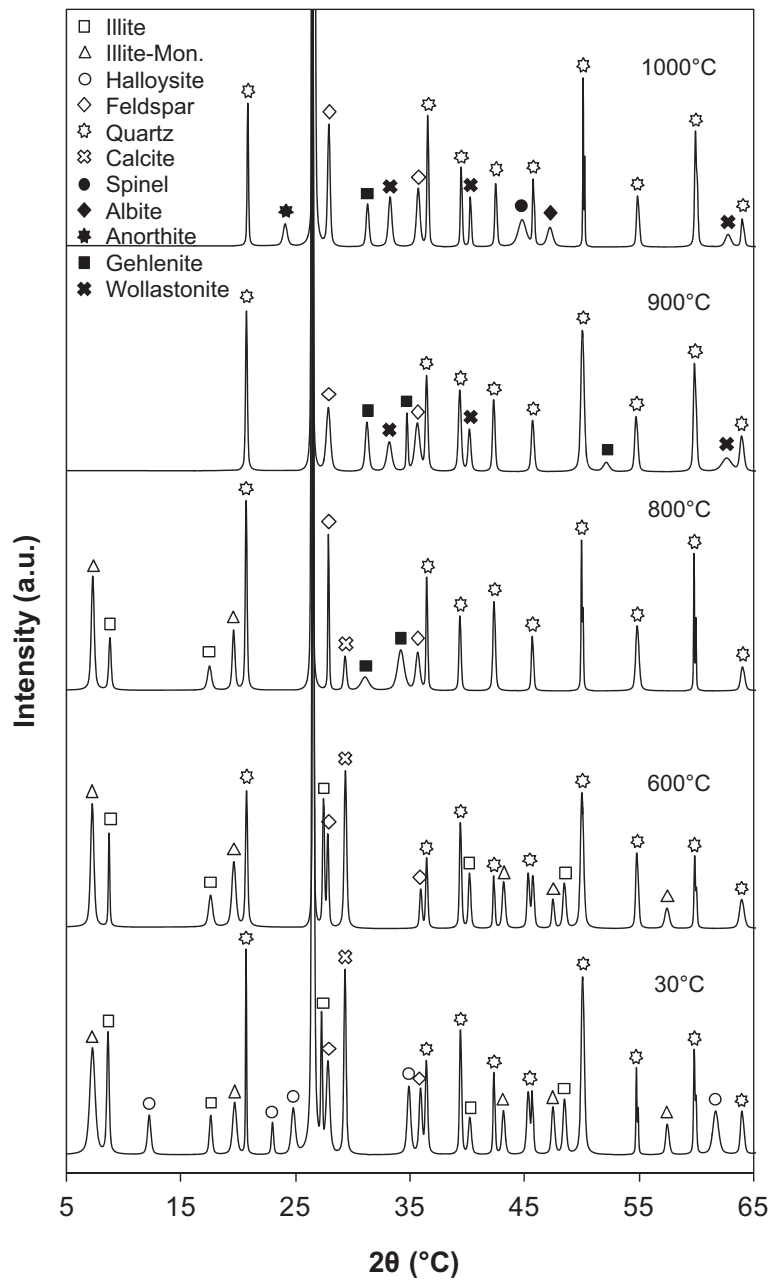

Fig. 2. X-ray diffraction patterns of the clay-based ceramic after heat treatment at $30{ }^{\circ} \mathrm{C}$, $600{ }^{\circ} \mathrm{C}, 800^{\circ} \mathrm{C}, 900^{\circ} \mathrm{C}$ and $1000^{\circ} \mathrm{C}$.

shown in Eq. (4).

$$
\mathrm{KAl}_{3} \mathrm{Si}_{3} \mathrm{O}_{10}(\mathrm{OH})_{2}(s) \rightarrow \mathrm{KAl}_{3} \mathrm{Si}_{3} \mathrm{O}_{11}(s)+\mathrm{H}_{2} \mathrm{O}(g)
$$

The transformations are related at higher temperatures to the clay minerals and the calcium carbonates. In fact, the temperature increase leads to a decarbonation of calcite from $650^{\circ} \mathrm{C}$ to $850^{\circ} \mathrm{C}$. The diffraction peaks of calcite (e.g., at $29^{\circ}$ ) are eliminated after heat treatment at $900^{\circ} \mathrm{C}$. However, no diffraction peak associated with a formation of lime is observed on the XRD patterns. The calcium oxides of calcite are combined with the residual aluminum and silicon oxides of the dehydroxylation [18]. Hence, the decarbonation transforms calcite and anhydrous illites into gehlenite $\left(\mathrm{Ca}_{2} \mathrm{Al}_{2} \mathrm{SiO}_{7}\right)$. The transformation induces a release of carbon dioxide $\left(\mathrm{CO}_{2}\right)$, amorphous silica $\left(\mathrm{SiO}_{2}\right)$ and alkalis $\left(\mathrm{K}_{2} \mathrm{O}\right)$ as shown in Eq. (5).

$$
\begin{aligned}
2 \mathrm{KAl}_{3} \mathrm{Si}_{3} \mathrm{O}_{11}(s)+6 \mathrm{CaCO}_{3}(s) & \rightarrow 3 \mathrm{Ca}_{2} \mathrm{Al}_{2} \mathrm{SiO}_{7}(s)+3 \mathrm{SiO}_{2}(\mathrm{~s})+\mathrm{K}_{2} \mathrm{O}(s) \\
& +6 \mathrm{CO}_{2}(g)
\end{aligned}
$$

The release of silicon and potassium oxides induces a convergence of the minerals towards the oxide equilibrium. The calcium oxides combine afterwards with the amorphous silica to form wollastonite $\left(\mathrm{CaSiO}_{3}\right)$ [19]. It explains the formation of wollastonite with a delay on the formation of gehlenite. The diffraction peaks associated with wollastonite are observed on the XRD patterns after heat treatment at $900{ }^{\circ} \mathrm{C}$. This transformation occurs at the end of the decarbonation with a release of carbon dioxide as shown in Eq. (6). The clay and calcium carbonates are eventually combined after heat treatment at $900{ }^{\circ} \mathrm{C}$. The $18 \mathrm{wt} \%$ of illite and $12 \mathrm{wt} \%$ of calcite produce $21 \mathrm{wt} \%$ of gehlenite and $13 \mathrm{wt} \%$ of wollastonite.

$$
\mathrm{CaCO}_{3}(s)+\mathrm{SiO}_{2}(s) \rightarrow \mathrm{CaSiO}_{3}(s)+\mathrm{CO}_{2}(g)
$$

The composition of the clay-based ceramic is modified by the recrystallization of kaolinitic-residues at higher temperatures. The halloysite obtains a sufficient amount of energy to reach an organization after the dehydroxylation from $450{ }^{\circ} \mathrm{C}$ [20]. The release of the last hydroxyl groups initiates a topotactic reaction at $950^{\circ} \mathrm{C}$. The transformation is observed on the XRD patterns with the diffraction peaks of the $\mathrm{Al} / \mathrm{Si}$ spinel phase by $1000{ }^{\circ} \mathrm{C}$. The $23 \mathrm{wt} \%$ of $\mathrm{Al} / \mathrm{Si}$ spinel phase at this temperature matches with the $26 \mathrm{wt} \%$ of halloysite prior to the heat treatment. However, no diffraction peaks associated with mullite can be observed on the XRD pattern. This mineral is unlikely to form due to the specific equilibrium of oxides.

$2 \mathrm{Al}_{2} \mathrm{Si}_{2} \mathrm{O}_{7}(s) \rightarrow \mathrm{Si}_{3} \mathrm{Al}_{4} \mathrm{O}_{12}(s)+\mathrm{SiO}_{2}(s)$

The mineralogical transformations of the clay-based ceramic are related to the minerals from the sand at temperatures higher than $1000{ }^{\circ} \mathrm{C}$. The diffraction peaks associated with albite $\left(\mathrm{NaAlSi}_{3} \mathrm{O}_{8}\right)$ and anorthite $\left(\mathrm{CaAl}_{2} \mathrm{Si}_{2} \mathrm{O}_{8}\right)$ appear on the XRD pattern as a result of the alkali feldspar degradation. The $3 \mathrm{wt} \%$ of albite and anorthite indicates a minor degradation of the $13 \mathrm{wt} \%$ of alkali feldspar at $1000{ }^{\circ} \mathrm{C}$ [21]. The clay-based ceramic is likely modified by a gas release associated with the mineralogical transformations. The clay-based ceramic is also modified by a solid-state sintering due to the absence of a liquid phase formation. In fact, the heat treatment provides some energy to the temperature-sensitive minerals of the clay-based ceramic mixture to reach the global equilibrium of oxides in a form of stable minerals.

\subsection{Impact of the mineralogical transformations on the microstructure}

The evolutions of the weight loss and of the deformation of the claybased ceramic during the heat treatment are displayed in Fig. 3. The heat treatment induces a dehydration of the clay-based ceramic from $30{ }^{\circ} \mathrm{C}$ to $250^{\circ} \mathrm{C}$. The dehydration leads to a $2 \mathrm{wt} \%$ elimination of water remaining in the pores of clay particles from $30^{\circ} \mathrm{C}$ to $100^{\circ} \mathrm{C}$. On the other hand, the $1 \mathrm{wt} \%$ elimination of water adsorbed on clay particles induces a shrinkage of the clay-based ceramic from $100^{\circ} \mathrm{C}$ up to $250^{\circ} \mathrm{C}$. The temperature increase also leads to a dehydroxylation of the clay minerals. The dehydroxylation of the kaolinite-group mineral induces a $1 \mathrm{wt} \%$ elimination of constitution water at around $450{ }^{\circ} \mathrm{C}$. Furthermore, a $1 \mathrm{wt} \%$ elimination of water is associated with the dehydroxylation of illites from $500{ }^{\circ} \mathrm{C}$ to $600{ }^{\circ} \mathrm{C}$. The temperature increase leads to a $\alpha \rightarrow \beta$ quartz inversion at around $600^{\circ} \mathrm{C}$ [22]. The quartz inversion induces an expansion of the quartz particles during

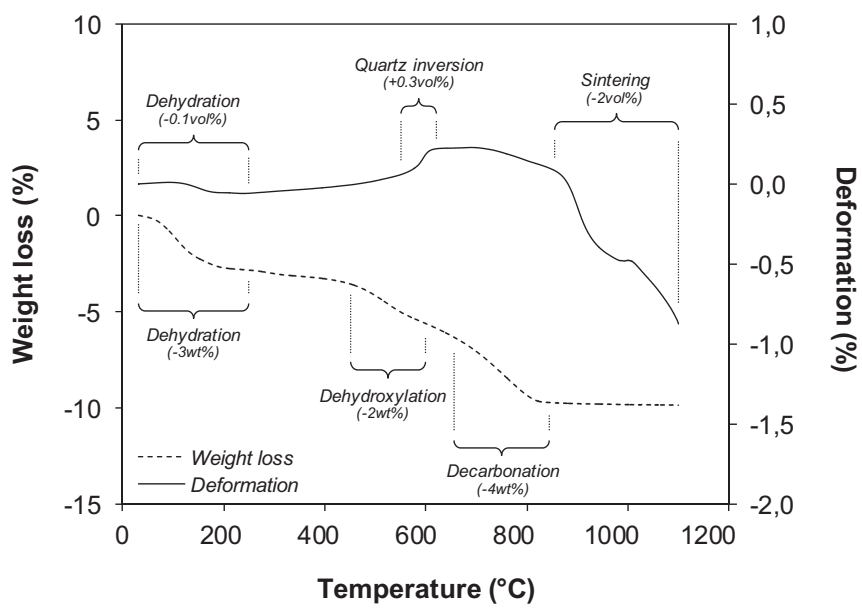

Fig. 3. Evolution of the weight loss and of the deformation of the clay-based ceramic during the heat treatment. 


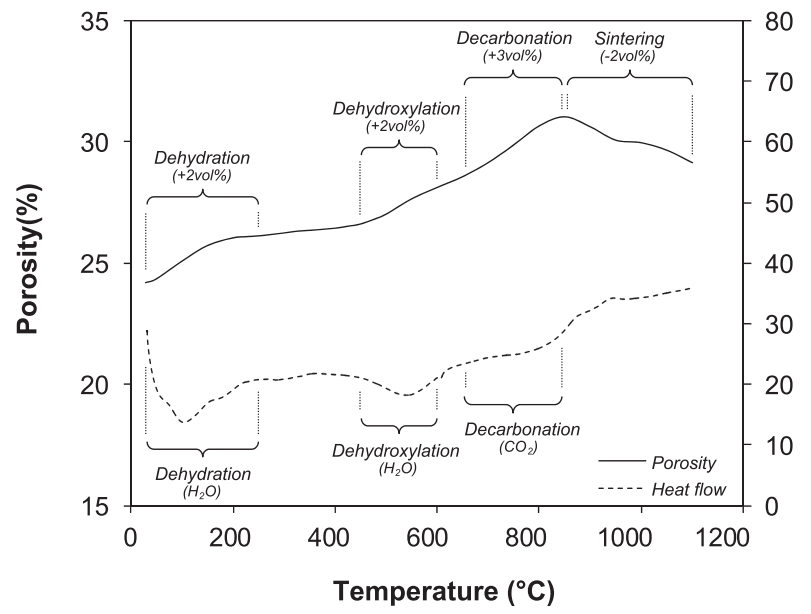

Fig. 4. Evolution of the porosity and of the heat flow of the clay-based ceramic during the heat treatment.

the heating of the clay-based ceramic. Furthermore, the shrinkage of the quartz particles results in a formation of defects during the $\beta \rightarrow a$ quartz inversion of the cooling. The heat treatment of the clay-based ceramic also leads to the decarbonation of the calcium carbonates. The decarbonation induces a $4 \mathrm{wt} \%$ elimination of calcite from $650{ }^{\circ} \mathrm{C}$ to $850^{\circ} \mathrm{C}$. On the same range of temperature, the clay-based ceramic experiences a solid-state sintering. The formation of necks between the particles leads to a shrinkage of the clay-based ceramic. However, the decarbonation limits the impact of the sintering to a consolidation of the clay-based ceramic up to $850^{\circ} \mathrm{C}$. The sintering only leads to a densification on a range of temperatures from $850^{\circ} \mathrm{C}$ to $1100^{\circ} \mathrm{C}$.

The evolution of the porosity during the heat treatment of the claybased ceramic is displayed in Fig. 4. The clay-based ceramic presents a porosity of $24 \mathrm{vol} \%$ after heat treatment at $30^{\circ} \mathrm{C}$. The air remaining in the mixture is trapped in the clay-based ceramic as pores during the extrusion process. Furthermore, the porosity is increased by the water release during the drying process. The heat treatment of the clay-based ceramic induces a 2 vol\% formation of porosity during the dehydration. The porosity formation can be related to the release of water remaining in the pores of clay particles from $30^{\circ} \mathrm{C}$ to $100^{\circ} \mathrm{C}$. Furthermore, the formation of porosity with the release of water absorbed on clay particles is limited by the shrinkage from $100{ }^{\circ} \mathrm{C}$ to $250{ }^{\circ} \mathrm{C}$. The dehydroxylation of the clay minerals also leads to a 2 vol\% formation of porosity between $450{ }^{\circ} \mathrm{C}$ and $600{ }^{\circ} \mathrm{C}$. The porosity formation can be related to the release of constitution water from the kaolinite-group and illite-group minerals. The release of carbon dioxide associated with the decarbonation of calcite induces a 3 vol\% formation of porosity from $650{ }^{\circ} \mathrm{C}$ to $850^{\circ} \mathrm{C}$. Therefore, the sintering does not reduce the porosity on this range of temperatures. The consolidation of the claybased ceramic consists in a coalescence of pores instead of an elimination [23]. The sintering only leads to a 2 vol\% reduction of the porosity during the densification from $850{ }^{\circ} \mathrm{C}$ to $1100{ }^{\circ} \mathrm{C}$. Hence, the clay-based ceramic conserves a $29 \mathrm{vol} \%$ of porosity at the highest heat treatment temperature of $1100{ }^{\circ} \mathrm{C}$.

The microstructure of the clay-based ceramic after heat treatment at $950{ }^{\circ} \mathrm{C}$ is displayed in Fig. 5. The cross-section micrograph shows a heterogeneous microstructure of clay with pores, feldspar and quartz particles. The $200 \mu \mathrm{m}$ pores orientated in a same direction result from the presence of air in the mixture during the extrusion process. In fact, the extrusion of process leads to a compression of the clay in the form of sheets. The air remaining in the mixture is then compressed between the sheets of clay in a form of porosity sheets. The set of porosity sheets also results in the formation of a layered microstructure, as shown on the 3D representation. Hence, the clay-based ceramic develop an anisotropic behavior as soon as the extrusion process. It is important to note that the layered microstructure is conserved after heat treatment of the clay-based ceramic at a temperature of $950{ }^{\circ} \mathrm{C}$. The formation of pores during the mineralogical transformations does not eliminate the anisotropy. The anisotropic behavior associated with the porosity sheets is not either eliminated during the sintering. In fact, the sintering of the clay-based ceramic decreases the percentage of porosity between $850^{\circ} \mathrm{C}$ and $1100{ }^{\circ} \mathrm{C}$ by an elimination of the smallest pores. The pores generated during the mineralogical transformations are then the smallest pores of the clay-based ceramic. The cross-section micrograph also shows the white particles of feldspar and angular particles of quartz. It can be noted a presence of large defects around the quartz particles. In fact, the defects are due to the larger shrinkage of quartz than clay particles during the $\beta \rightarrow \alpha$ quartz inversion of the cooling. These defects associated with the quartz particles from the sand represent the largest defects in the microstructure with the porosity sheets of the extrusion process.

\subsection{Impact of the microstructure evolution on the thermal properties}

The evolution of the thermal conductivity with the heat treatment temperature is shown in Fig. 6 . The clay-based ceramic presents a thermal conductivity of $1.07 \mathrm{~W} / \mathrm{m} / \mathrm{K}$ after heat treatment at $30^{\circ} \mathrm{C}$. This value represents a combination between the relatively high thermal conductivity of the solid skeleton and the relatively low thermal conductivity of air in the porosity sheets. The contribution of the solid skeleton can be determined from the Landauer's model [24], reexpressed in Eq. (8) where $\lambda$ is the measured thermal conductivity of the clay-based ceramic, $\lambda_{\mathrm{s}}$ is the thermal conductivity of the solid skeleton, $\lambda_{\mathrm{p}}$ is the thermal conductivity of air in the porosity, and $\mathrm{v}_{\mathrm{p}}$ is the pore volume fraction obtained from the percentage of porosity. It is important to note that the thermal conductivity of the solid skeleton is estimated at room temperature with the values of the pore volume fraction in temperature. This was only possible as the pore volume fraction of the clay-based ceramic at room temperature was equivalent to the pore volume fraction in temperature.

$\lambda_{\mathrm{s}}=\frac{2 \lambda^{2}-\lambda \lambda_{\mathrm{p}}\left(3 \mathrm{v}_{\mathrm{p}}-1\right)}{\lambda_{\mathrm{p}}+\lambda\left(2-3 \mathrm{v}_{\mathrm{p}}\right)}$

According to the Landauer's model, the thermal conductivity of the solid skeleton is equal to $1.69 \mathrm{~W} / \mathrm{m} / \mathrm{K}$ after heat treatment of the claybased ceramic at $30^{\circ} \mathrm{C}$. On the other hand, the thermal conductivity of air is equal to $0.026 \mathrm{~W} / \mathrm{m} / \mathrm{K}$. It is important to note that the impact of air on the thermal conductivity of the clay-based ceramic is enhanced in this direction of the thermal gradient of the walls by the anisotropic behavior of the porosity sheets.

The dehydration induces a $7 \%$ decrease of the thermal conductivity at temperatures between $30^{\circ} \mathrm{C}$ and $250{ }^{\circ} \mathrm{C}$. The thermal conductivity of the clay-based ceramic is decreased by the 2 vol\% formation of porosity since the mineral phases are not transformed on this range of temperatures. In fact, the porosity formation reduces the proportion of solid skeleton with a relatively high thermal conductivity. The thermal conductivity of the clay-based ceramic is also decreased by the relatively low thermal conductivity of air in the newly-formed pores.

The dehydroxylation of the clay minerals also results in a $23 \%$ decrease of the thermal conductivity. The decrease of the thermal conductivity is related to the $2 \mathrm{vol} \%$ formation of porosity from $450{ }^{\circ} \mathrm{C}$ to $600{ }^{\circ} \mathrm{C}$. According to the Landauer's model, the porosity formation represents a $4 \%$ decrease of the thermal conductivity. The thermal conductivity of the clay-based ceramic is then also decreased by a modification of the solid skeleton. The modification of the solid skeleton concerns the kaolinite-group mineral since the clay minerals from other groups only recombine with calcite at temperatures between $650^{\circ} \mathrm{C}$ and $850{ }^{\circ} \mathrm{C}$. In fact, the kaolinite-group mineral with a thermal conductivity approximated to the $2.80 \mathrm{~W} / \mathrm{m} / \mathrm{K}$ one of kaolinite [25], transform from $450{ }^{\circ} \mathrm{C}$ to $600{ }^{\circ} \mathrm{C}$ into metakaolin with a thermal 


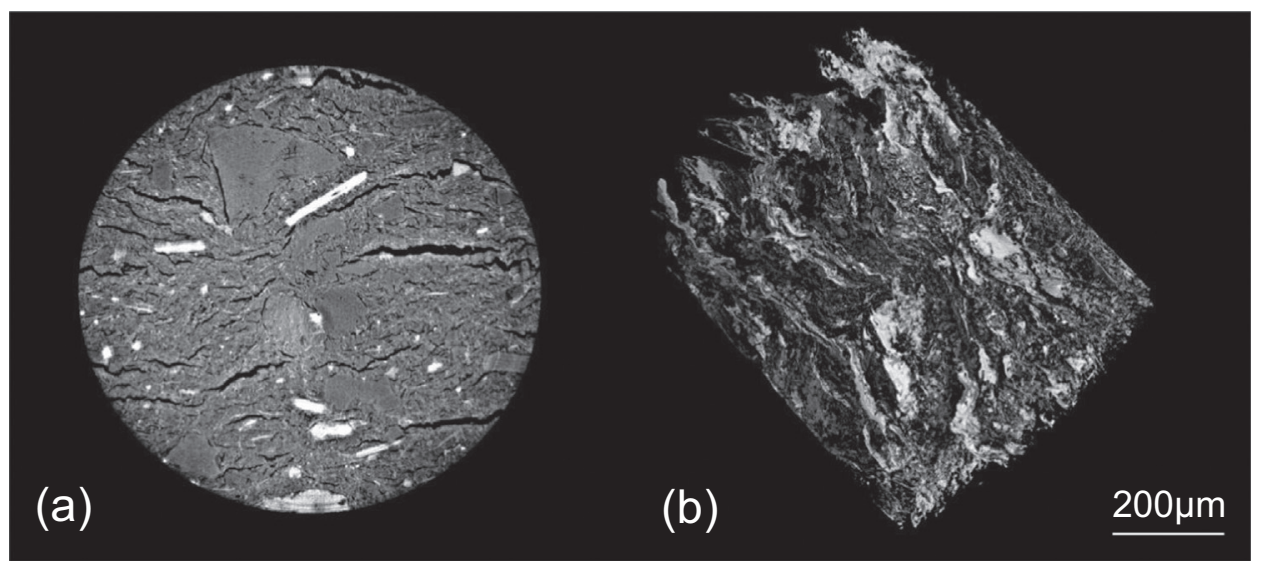

Fig. 5. X-ray tomography micrograph of the cross-section (a) and 3D representation of the porosity (b) of the clay-based ceramic after heat treatment at $950{ }^{\circ} \mathrm{C}$.

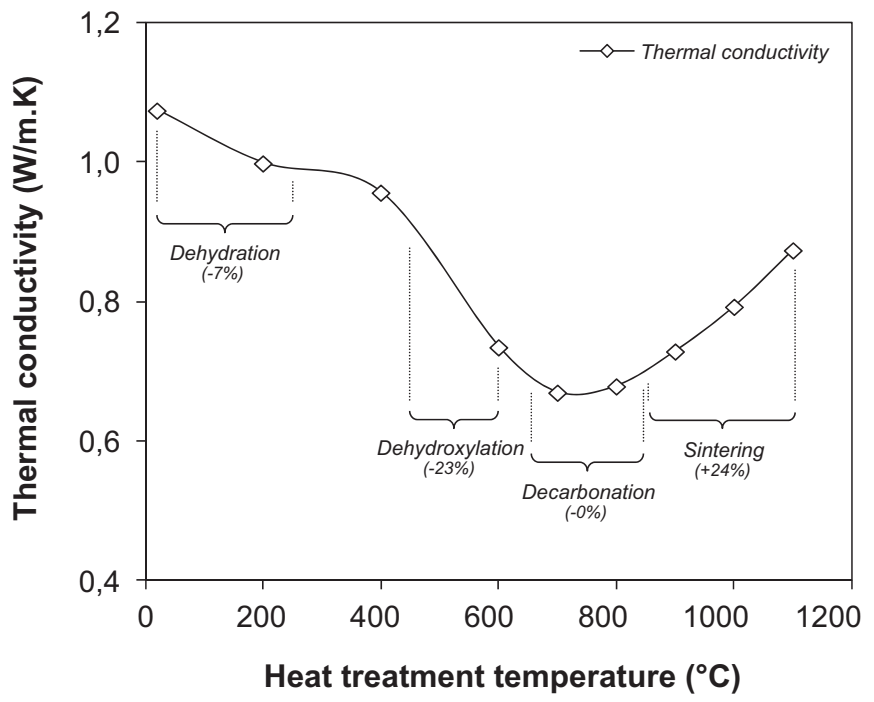

Fig. 6. Evolution of the Young's modulus of the clay-based ceramic during the heating and cooling.

conductivity of $0.39 \mathrm{~W} / \mathrm{m} / \mathrm{K}$ [26]. The $26 \mathrm{wt} \%$ formation of metakaolin results in an extensive decrease of the thermal conductivity of the solid skeleton. According to the Landauer's model, the thermal conductivity of the solid skeleton is decreased from $1.55 \mathrm{~W} / \mathrm{m} / \mathrm{K}$ to $1.23 \mathrm{~W} / \mathrm{m} / \mathrm{K}$. This modification of the solid skeleton represents a $20 \%$ decrease in the thermal conductivity of the clay-based ceramic.

The decarbonation of calcite does not significantly modify the thermal conductivity of the clay-based ceramic. The 3 vol\% formation of porosity results, according to the Landauer's model, in a $6 \%$ decrease of the thermal conductivity from $650{ }^{\circ} \mathrm{C}$ to $850{ }^{\circ} \mathrm{C}$. However, the impact of the porosity formation is prevented by the modification of the solid skeleton. The illite-group minerals and calcite, with thermal conductivities of $1.80 \mathrm{~W} / \mathrm{m} / \mathrm{K}$ and $3.40 \mathrm{~W} / \mathrm{m} / \mathrm{K}$ [25], combine on this range of temperatures into gehlenite and wollastonite, with thermal conductivities of $1.53 \mathrm{~W} / \mathrm{m} / \mathrm{K}$ and $4.03 \mathrm{~W} / \mathrm{m} / \mathrm{K}$ [27]. The $21 \mathrm{wt} \%$ formation of gehlenite and $13 \mathrm{wt} \%$ formation of wollastonite induces a significant increase in the thermal conductivity of the solid skeleton. According to the Landauer's model, the thermal conductivity of the solid skeleton is increased from $1.25 \mathrm{~W} / \mathrm{m} / \mathrm{K}$ to $1.33 \mathrm{~W} / \mathrm{m} / \mathrm{K}$ which represents a $6 \%$ increase in the thermal conductivity of the clay-based ceramic.

The sintering of the clay-based ceramic induces a $24 \%$ increase of the thermal conductivity from $850^{\circ} \mathrm{C}$ to $1100^{\circ} \mathrm{C}$. The thermal conductivity of the clay-based ceramic is increased by the 2 vol\% reduction of the porosity. The lower proportion of air represents, according to the Landauer's model, a $5 \%$ increase of the thermal conductivity. The thermal conductivity of the clay-based ceramic is also increased by the modification of the solid skeleton. In fact, the metakaolin with a thermal conductivity of $0.39 \mathrm{~W} / \mathrm{m} / \mathrm{K}$ [26] recrystallizes on this range of temperature into an $\mathrm{Al} / \mathrm{Si}$ spinel phase with a thermal conductivity of $0.56 \mathrm{~W} / \mathrm{m} / \mathrm{K}$ [26]. The $23 \mathrm{wt} \%$ formation of $\mathrm{Al} / \mathrm{Si}$ spinel leads to an extensive increase in the thermal conductivity of the solid skeleton. According to the Landauer's model, the thermal conductivity of the solid skeleton is increased from $1.33 \mathrm{~W} / \mathrm{m} / \mathrm{K}$ to $1.58 \mathrm{~W} / \mathrm{m} / \mathrm{K}$. This modification of the solid skeleton represents a $19 \%$ increase in the thermal conductivity of the clay-based ceramic. Hence, the clay-based ceramic has a thermal conductivity of $0.87 \mathrm{~W} / \mathrm{m} / \mathrm{K}$ after heat treatment at $1100{ }^{\circ} \mathrm{C}$.

\subsection{Impact of the microstructure evolution on the mechanical properties}

The evolution of the Young's modulus during the heat treatment of the clay-based ceramic is displayed in Fig. 7. The clay-based ceramic presents a Young's modulus of $7.5 \mathrm{GPa}$ after heat treatment at $30^{\circ} \mathrm{C}$. The stiffness is obtained by formation of a solid skeleton during the extrusion process. However, the stiffness is also restrained by the $200 \mu \mathrm{m}$ sheets of porosity acting as defects.

The heat treatment of the clay-based ceramic induces a $76 \%$ increase of the Young's modulus during the dehydration. The porosity formation could decrease the Young's modulus from $30^{\circ} \mathrm{C}$ to $250{ }^{\circ} \mathrm{C}$. However, the positive impact of the shrinkage exceeds the negative

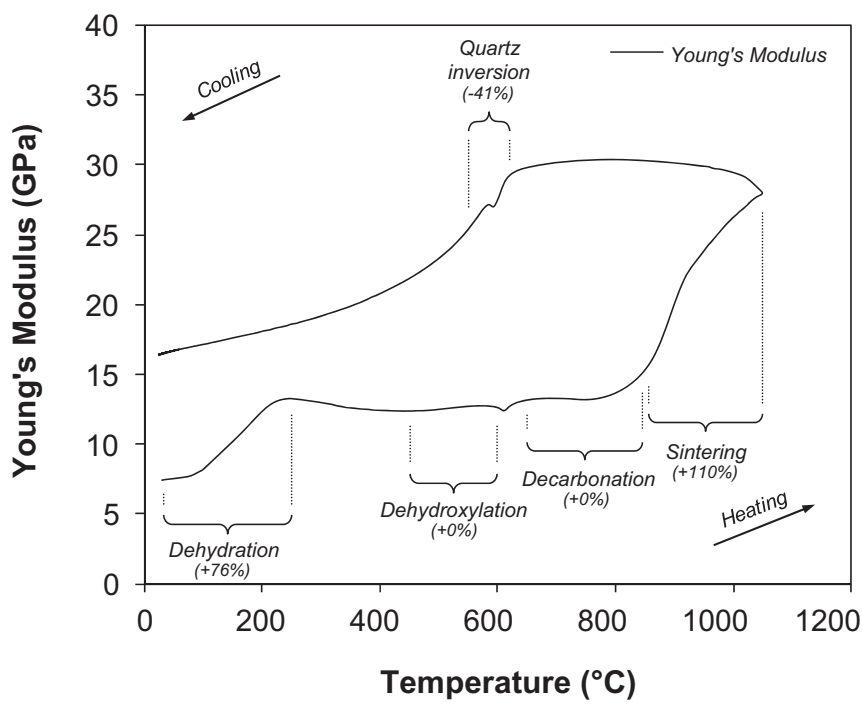

Fig. 7. Evolution of the thermal conductivity of the clay-based ceramic with the heat treatment temperature. 
impact of the pores on this range of temperatures.

The dehydroxylation of the clay minerals does not induce any modification of the Young's modulus at temperatures between $450{ }^{\circ} \mathrm{C}$ and $600{ }^{\circ} \mathrm{C}$. The Young's modulus of the clay-based ceramic is not increased on this range of temperatures due the amorphization of the kaolinite-group mineral as well as the absence of shrinkage. The Young's modulus is not decreased either by the newly-formed pores acting as defects. In fact, the dehydroxylation of the clay minerals results in a formation of small pores compared to the $200 \mu \mathrm{m}$ porosity sheets of the extrusion process. This result suggests that the formation of smaller pores than the previous defects of the microstructure allows a conservation of the Young's modulus.

The decarbonation of the calcium carbonates does not result in any modification of the Young's modulus at temperatures between $650{ }^{\circ} \mathrm{C}$ and $850^{\circ} \mathrm{C}$. The Young's modulus of the clay-based ceramic is increased by the formation of stable minerals such as gehlenite and wollastonite. The consolidation of the clay-based ceramic also leads to an increase of the Young's modulus on this range of temperatures. But, the positive impact of the calcium-rich crystallites along with the formation of necks between the clay particles is prevented by the coalescence of pores. This increase in the pore size of the clay-based ceramic enhances the negative impact of the $3 \mathrm{vol} \%$ formation of porosity on the Young's modulus.

The sintering only increases the Young's modulus after the decarbonation of the calcium carbonates. The densification of the claybased ceramic along with the crystallization of metakaolin into an $\mathrm{Al} / \mathrm{Si}$ spinel phase induces a $110 \%$ increase of the Young's modulus at temperatures between $850^{\circ} \mathrm{C}$ and $1050{ }^{\circ} \mathrm{C}$. Hence, the clay-based ceramic presents a Young's modulus of $27.9 \mathrm{GPa}$ at the highest heat treatment temperature.

However, the Young's modulus is decreased by $41 \%$ during the cooling of the clay-based ceramic. The decrease in the Young's modulus can be related to the $\beta \rightarrow \alpha$ quartz inversion at around $600{ }^{\circ} \mathrm{C}$. In fact, the transition leads to a formation of large defects around the quartz particles from the sand. This means that a formation of defects as large as the $200 \mu \mathrm{m}$ sheets of porosity have a predominant impact on the Young's modulus. Hence, the clay-based ceramic presents a Young's modulus of $16.4 \mathrm{GPa}$ after the cooling.

The sand is added in the clay-based ceramic mixture to promote a fast elimination of water during the drying process. However, a small reduction in the amount of sand could reduce the formation of defects at the quartz inversion. The clay-based ceramic could present a higher Young's modulus after the cooling.

\subsection{Implications}

The implications of this work are significant in the field of building materials. The building materials such as fired clay bricks are used for their thermal and mechanical properties. The literature has shown a major impact of the percentage of porosity. The insulating behavior of air in the pores provided high thermal properties to the fired clay bricks. Nevertheless, the mechanical properties were limited by the pores acting as defects in the microstructure. The fired clay bricks presented a trade-off between their thermal and mechanical properties.

The thermal properties of a clay-based ceramic were improved with a conservation of the mechanical properties in this study. The improvement was based on a formation of smaller pores than the defects of the microstructure. In fact, the pores generated during the heat treatment were smaller than large porosity sheets formed during the extrusion process. The porosity increase along with the development of metakaolin led to a $38 \%$ improvement of the thermal properties. The mechanical properties of the clay-based ceramic were only reduced during the $\beta \rightarrow \alpha$ quartz inversion of the cooling. In fact, the decrease in the mechanical properties was caused by the quartz particles from the sand. The large grain size of the sand promotes a fast elimination of water during the drying process. But, a small reduction in the amount of sand could improve the mechanical properties of the fired clay bricks.

This research also provided information for a larger improvement of the properties using organic additives. The combustion of organic additives in fired clay bricks should lead to a porosity formation during the heat treatment. Hence, the porosity increase would improve the thermal properties of the fired clay bricks. The mechanical properties could also be conserved by addition of smaller particles than the defects of the microstructure. This information could widen the range of organic additives used in fired clay bricks to many organic wastes.

\section{Conclusions}

This study investigated the impact of heat treatment on the microstructure of a clay-based ceramic and its thermal and mechanical properties. The heat treatment of the clay-based ceramic induced a transformation of the temperature-sensitive minerals towards the global equilibrium of oxides. The clay mineral of the kaolinite-group transformed into amorphous metakaolin to recrystallize in $\mathrm{Al} / \mathrm{Si}$ spinel phase. Furthermore, the illite-group minerals and calcite combined into calcium-rich crystallites such as gehlenite and wollastonite. The gas release associated with these transformations induced a porosity formation in the clay-based ceramic. The thermal properties of the clay-based ceramic were then improved by the low thermal conductivity of air in the newly-formed pores after a heat treatment at $850^{\circ} \mathrm{C}$. The improvement of the thermal properties was also due to the formation of metakaolin which decreased the thermal conductivity of the solid skeleton. On the other hand, the mechanical properties of the clay-based ceramic were conserved due to the formation of smaller pores than the defects of the microstructure. The densification of the clay-based ceramic along with the crystallization of amorphous phases also resulted in an improvement of the mechanical properties. The mechanical properties of the clay-based ceramic were only decreased during the $\beta \rightarrow \alpha$ quartz inversion of the cooling as a result of the sand addition. Hence, this study provided a useful insight into how the microstructure of fired clay bricks can be specifically transformed by the porosity during the heat treatment to control the thermal and mechanical properties.

\section{Funding}

This study was funded by Agence Nationale de la Recherche et de la Technologie (CIFRE N²011/1193).

\section{Conflict of interest}

The authors declare that they have any conflict of interest.

\section{Acknowledgements}

The authors would like to acknowledge the TERREAL Company for financial support and scientific contribution to this study. We also thank the staff of the ICA and RAPSODEE Centers at Ecole des Mines d'Albi for assistance with the research. Mr. Daniel Davidson and Mr. Wesley Awe are also thanked for proofreading this manuscript.

\section{References}

[1] W.M. Carty, U. Senapati, Porcelain-raw materials, processing, phase evolution, and mechanical behavior, J. Am. Ceram. Soc. 81 (1998) 3-20.

[2] K.J. Krakowiak, P.B. Lourenço, F.J. Ulm, Multitechnique investigation of extruded clay brick microstructure, J. Am. Ceram. Soc. 94 (2011) 3012-3022.

[3] M.M. Jordan, M.A. Montero, S. Meseguer, T. Sanfeliu, Influence of firing temperature and mineralogical composition on bending strength and porosity of ceramic tile bodies, Appl. Clay Sci. 42 (2008) 266-271.

[4] M. Dondi, M. Marsigli, B. Fabbri, Recycling of industrial and urban wastes in brick production - a review, Tile Brick Int. 13 (1997) 218-225.

[5] N.S. Müller, V. Kilikoglou, P.M. Day, G. Vekinis, The influence of temper shape on 
the mechanical properties of archaeological ceramics, J. Eur. Ceram. Soc. 30 (2010) 2457-2465.

[6] J.G. Ten, M.J. Orts, A. Saburit, G. Silva, Thermal conductivity of traditional ceramics. Part I: influence of bulk density and firing temperature, Ceram. Int. 36 (2010) 1951-1959.

[7] D.S. Smith, A. Alzina, J. Bourret, B. Nait-Ali, F. Pennec, N. Tessier-Doyen, K. Otsu, H. Matsubara, P. Elser, U.T. Gonzenbach, Thermal conductivity of porous materials, J. Mater. Res. 28 (2013) 2260-2272.

[8] J. Bourret, N. Tessier-Doyen, R. Guinebretiere, E. Joussein, D.S. Smith, Anisotropy of thermal conductivity and elastic properties of extruded clay-based materials: evolution with thermal treatment, Appl. Clay Sci. 116-117 (2015) 150-157.

[9] D.V. Andreev, A.I. Zakharov, Ceramic item deformation during firing: effects of composition and microstructure (review), Refract. Ind Ceram. 50 (2009) 298-303.

[10] H.S. Kim, T. Guifang, J.Y. Kim, Clayware mechanical properties porosity dependent, Am. Ceram. Soc. Bull. 81 (2002) 20-25.

11] S.N. Monteiro, C.M.F. Silva, Solid state sintering of red ceramics at lower temperatures, Ceram. Int. 30 (2004) 381-387.

[12] P. Pialy, N. Tessier-Doyen, D. Njopwouo, J.P. Bonnet, Effects of densification and mullitization on the evolution of the elastic properties of a clay-based material during firing, J. Eur. Ceram. Soc. 29 (2009) 1579-1586.

[13] S. Freyburg, A. Schwarz, Influence of the clay type on the pore structure of structural ceramics, J. Eur. Ceram. Soc. 27 (2007) 1727-1773.

[14] S.K. Rhee, Porosity-thermal conductivity correlations for ceramic materials, Mater Sci. Eng. 20 (1975) 89-93.

[15] S. Bailliez, A. Nzihou, The kinetics of surface area reduction during isothermal sintering of hydroxyapatite adsorbent, Chem. Eng. J. 98 (2004) 141-152.

[16] A. Aras, The change of phase composition in kaolinite and illite-rich clay-based ceramic bodies, Appl. Clay Sci. 24 (2004) 257-269.

17] A.F. Gualtieri, S. Ferrari, Kinetics of illite dehydroxylation, Phys. Chem. Miner. 33 (2006) 490-501.

[18] T. Peters, R. Iberg, Mineralogical changes during firing of calcium-rich brick clays, Ceram. Bull. 57 (1978) 503-509.

[19] G. Cultrone, C. Rodriguez-Navarro, E. Sebastian, O. Cazalla, M.J. De La Torre, Carbonate and silicate phase reactions during ceramic firing, Eur. J. Miner. 13 (2001) 621-634.

[20] B. Sonuparlak, M. Sarikaya, I.A. Aksay, Spinel phase formation during the $980^{\circ} \mathrm{C}$ exothermic reaction in the kaolinite-to-mullite reaction series, J. Am. Ceram. Soc. 70 (1987) 837-842.

[21] M. Krichen, J.P. Bonnet, J. Bouaziz, S. Baklouti, Mineralogy and sintering mechanisms of a clay raw material from Kasrine, Silic. Ind. 74 (2009) 139-144.

[22] T. Tarvornpanich, G.P. Souza, W.E. Lee, Microstructural evolution in clay-based ceramics II: ternary and quaternary mixtures of clay, flux, and quartz filler, J. Am. Ceram. Soc. 91 (2008) 2272-2280.

[23] V. Ducman, A.S. Škapin, M. Radeka, J. Ranogajec, Frost resistance of clay roofing tiles: case study, Ceram. Int. 37 (2011) 85-91.

[24] R. Landauer, The electrical resistance of binary metallic mixtures, J. Appl. Phys. 23 (1952) 779-784.

[25] K. Midttømme, E. Roaldset, P. Aagaard, Thermal conductivity of selected claystones and mudstones from England, Clay Miner. 33 (1998) 131-145.

[26] A. Michot, D.S. Smith, S. Degot, C. Gault, Thermal conductivity and specific heat of kaolinite: evolution with thermal treatment, J. Eur. Ceram. Soc. 28 (2008) 2639-2644.

[27] K. Horai, G. Simmons, Thermal conductivity of rock-forming minerals, Earth Planet. Sci. Lett. 6 (1969) 359-368. 